\title{
Phenotypic relationships between docility and reproduction in Angus heifers ${ }^{1}$
}

\author{
K. L. White,*2 J. M. Bormann,* K. C. Olson,* J. R. Jaeger,* S. Johnson,* B. Downey, $\dagger$ \\ D. M. Grieger,* J. W. Waggoner,* D. W. Moser,* and R. L. Weaber* \\ *Department of Animal Sciences and Industry, Kansas State University, Manhattan 66506; \\ and †Downey Ranch Inc., Wamego, KS 66547
}

\begin{abstract}
The objective of this study was to elucidate the phenotypic relationships between docility and first-service AI conception rate in heifers. Data $(n$ $=337$ ) collected from 3 cooperator herds in Kansas at the start of synchronization protocol included exit velocity (EV), chute score (CS), fecal cortisol (FC), and blood serum cortisol (BC). Data were analyzed using logistic regression with 30 -d pregnancy rate as the dependent variable. The model included the fixed effect of contemporary group and the covariates FC, $\mathrm{BC}, \mathrm{EV}, \mathrm{CS}, \mathrm{BW}$, and age. Correlation coefficients were calculated between all continuous traits. Pregnancy rate ranged from $34 \%$ to $60 \%$ between herds. Blood cortisol positively correlated with EV $(r=$ $0.22, P<0.01)$, negatively correlated with age $(r=$ $-0.12, P<0.03)$, and tended to be negatively correlated with $\mathrm{BW}(r=-0.10, P=0.09)$. Exit velocity was positively correlated with $\mathrm{CS}(r=0.24, P<0.01)$ and negatively correlated with BW $(r=-0.15, P<$
\end{abstract}

$0.01)$ and age $(r=-0.12, P<0.03)$. Chute score negatively correlated with age $(r=-0.14, P<0.01)$, and age and BW were moderately positively correlated $(r$ $=0.42, P<0.01)$, as expected. Older, heavier animals generally had better temperament, as indicated by lower BC, EV, and CS. The power of our test could detect no significant predictors of 30-d pregnancy for the combined data from all ranches. When the data were divided by ranch, $\mathrm{CS}(P<0.03)$ and BW $(P<$ 0.01 ) were both significant predictors for 30 -d pregnancy for ranch 1 . The odds ratio estimate for CS has an inverse relationship with pregnancy, meaning that a 1-unit increase in average CS will reduce the probability of pregnancy at ranch 1 by $48.1 \%$. Weight also has a negative impact on pregnancy because a $1-\mathrm{kg}$ increase in BW will decrease the probability of pregnancy by $2.2 \%$. Fertility is a complex trait that depends on many factors; our data suggest that docility is 1 factor that warrants further investigation.

Key words: beef cattle, docility, fertility, genetics, pregnancy

(C) 2016 American Society of Animal Science. All rights reserved.

\section{INTRODUCTION}

Reproductive success is vital to the financial success of beef cattle operations because income generated by the sale of calves is often a large portion of an operation's income. Selecting for fertility is difficult because it is influenced by a variety of fac-

\footnotetext{
${ }^{1}$ Kansas Agricultural Experiment Station contribution 15-352-J. The authors acknowledge the contribution of the American Angus Association to this study.

${ }^{2}$ Corresponding author: kotteman@k-state.edu

Received May 18, 2015.

Accepted November 5, 2015.
}

tors (Cammack et al., 2009). Temperament is a factor that requires further investigation. Physiological responses associated with temperament can influence the probability of cows becoming pregnant because stress hormones in the bloodstream can negatively affect the release of reproductive hormones (Cooke et al., 2009). Differences in concentrations of circulating stress hormones have been associated with differences in cattle temperament (Curley et al., 2006). Cattle with "calm" temperaments had lower serum cortisol and epinephrine concentrations than animals classified as "temperamental" at a commercial feed yard (Curley et al., 2006). 
Methods have been developed to assess temperament in cattle. Exit velocity (EV) measures the time required for an animal to cover a predetermined distance after vacating the chute (Burrow et. al., 1988). Chute scores (CS) range from 1 (quiet) to 6 (aggressive) and are based on the animal's behavior when confined in a chute (Curley et. al., 2006). Positive correlations of $\mathrm{CS}$ and $\mathrm{EV}$ with cortisol indicate that both scores are reliable indicators of temperament (Cooke et al., 2009).

Handling of cattle is associated with changes in concentrations of stress hormones. Blood serum collection can provide insight into acute stressors (Curley et al., 2006). Fecal sampling can be reflective of chronic stress experienced 2 to $3 \mathrm{~d}$ before sampling (Huber et al., 2003).

The objective of this study was to elucidate relationships between docility and pregnancy rate. We hypothesized that differences in temperament scores and associated cortisol levels of heifers would be associated with differences in pregnancy rate.

\section{MATERIALS AND METHODS}

\section{Data Collection}

This research was conducted according to protocols approved by the Institutional Animal Care and Use Committee at Kansas State University. Data for this project were collected from 3 different cooperator herds, 2 of which were affiliated with Kansas State University. Ranches 1 and 2 were located in the Flint Hills of northeast Kansas, and ranch 3 was in central Kansas. A total of 337 yearling heifers were used in this study.

Ranch $1(n=117)$ heifers were synchronized using a combined melengestrol acetate (MGA)/ $\mathrm{PGF}_{2 \alpha} / \mathrm{GnRH}$ (Cystorelin, Merial, Duluth, GA) synchronization protocol. Melengestrol acetate was fed at $0.5 \mathrm{mg}$ per heifer per day for $14 \mathrm{~d}$. On d 33 ( $19 \mathrm{~d}$ following the final feeding of MGA), $5 \mathrm{~mL}$ of $\mathrm{PGF}_{2 \alpha}$ (Lutalyse, Zoetis, Florham Park, NJ) was injected intramuscularly, EV and CS were recorded, and fecal samples were collected for cortisol analysis. Heifers were then visually detected for estrus for $2 \mathrm{~d}$ and bred 10 to $14 \mathrm{~h}$ after observed estrus. On $\mathrm{d} 3$ after $\mathrm{PGF}_{2 \alpha}$ injection (d 36), all females not previously detected in estrus were injected with $2 \mathrm{~mL}$ of $\mathrm{GnRH}$ and inseminated. Blood samples were collected for cortisol analysis following insemination. Females were exposed to natural service sires on d 37, and transrectal ultrasonography was used to determine pregnancy at $30 \mathrm{~d}$. Ultrasonography was conducted by a trained technician who was unique to this location.

Ranches $2(n=133)$ and $3(n=87)$ employed identical Co-Synch + CIDR (controlled internal drug release) protocols to synchronize heifers. Controlled internal drug release inserts (EAZI-BREED CIDRs,
Zoetis) were inserted at $\mathrm{d} 0$, and heifers were given a 2-mL injection of GnRH. Exit velocity and CS were recorded at this time, and fecal samples were collected for cortisol analysis. Inserts were removed on $\mathrm{d} 7$, and a 2-mL injection of $\mathrm{PGF}_{2 \alpha}$ (Lutalyse, Zoetis) was administered. On d 9, the heifers received a 2-mL injection of GnRH and were inseminated. Blood samples were collected for cortisol analysis at this time. For an unrelated study, heifers were randomly assigned to 1 of 3 different protocols for target insemination: right uterine horn, left uterine horn, and uterine body. Heifers were assigned randomly to 1 of 2 treatments postbreeding, with the test group receiving a flunixin meglumine injection (Banamine, Intervet Inc., Merck Animal Health, Summit, NJ) 14 d postbreeding. Transrectal ultrasonography was used to determine pregnancy at $30 \mathrm{~d}$. Ultrasonography was conducted by a trained technician who was unique to each location.

Exit velocity is an objective measure of temperament that records the time taken in hundredths of a second for an animal to pass through 2 light beams separated by a distance of $1.7 \mathrm{~m}$ after leaving a squeeze chute (Burrow et al., 1988). The light beams focus on infrared receivers that trigger an on/off mechanism as the beams are broken.

Chute score is a subjective measure of temperament recommended by the Beef Improvement Federation (2010) to aid in genetic improvement of docility. Chute scores range from 1 to 6 ; a 1 represents calm, docile behavior, whereas a 6 represents aggressive, unacceptable behavior. An animal scored as a 1 will have a mild disposition, will handle quietly, and will exit the chute calmly. An animal scored as a 2 will be somewhat restless in the chute but will be quieter than average. The animal may be stubborn during processing, with some tail flicking, and will exit the chute promptly. An animal scored as a 3, which is average, will be manageable but impatient; the animal will continuously push and pull on the head gate and will exit the chute briskly. A 4 will be flighty and slightly wild and will be jumpy and struggle violently in the chute, with continuous tail flicking, and will exit the chute wildly. An animal with a score of 5 will resemble one scored as a 4 but with increased aggressive behavior, including extreme agitation and continuous movement that may involve jumping and bellowing while in the chute. An animal rated a 5 will also exit the chute frantically and may exhibit attack behavior when handled alone. A score of 6 indicates an animal that is extremely aggressive with pronounced attack behavior (Busby, 2010). A 1 or 2 score indicates highly acceptable behavior, 3 is average, and 4, 5, and 6 are deemed unacceptable (Beckman et al., 2005). Chute scores for this study were taken by 2 separate evaluators and averaged before data analysis. 
Table 1. Least squares means (LSM) and SE of fecal cortisol (FC), blood cortisol (BC), exit velocity (EV), chute score (CS), BW, and age by location

\begin{tabular}{|c|c|c|c|c|c|c|}
\hline \multirow[b]{2}{*}{ Variable } & \multicolumn{2}{|c|}{ Ranch 1} & \multicolumn{2}{|c|}{ Ranch 2} & \multicolumn{2}{|c|}{ Ranch 3} \\
\hline & $n$ & LSM & $n$ & LSM & $n$ & LSM \\
\hline$\overline{\mathrm{FC}, \mathrm{ng} / 0.5 \mathrm{~g}}$ & 115 & $142.69^{a} \pm 3.00$ & 132 & $95.21^{b} \pm 2.19$ & 86 & $125.89^{c} \pm 2.65$ \\
\hline $\mathrm{BC}, \mathrm{ng} / \mathrm{mL}$ & 117 & $34.99^{\mathrm{a}} \pm 1.90$ & 132 & $39.11^{\mathrm{a}} \pm 1.89$ & 87 & $51.79^{b} \pm 2.14$ \\
\hline $\mathrm{EV}, \mathrm{m} / \mathrm{s}$ & 116 & $1.57^{\mathrm{a}} \pm 0.05$ & 130 & $1.94^{\mathrm{b}} \pm 0.07$ & 83 & $2.27^{c} \pm 0.10$ \\
\hline $\mathrm{CS}^{1}$ & 117 & $2.19^{\mathrm{a}} \pm 0.07$ & 133 & $1.50^{\mathrm{b}} \pm 0.05$ & 87 & $2.00^{c} \pm 0.08$ \\
\hline $\mathrm{BW}, \mathrm{kg}$ & 117 & $351.71^{\mathrm{a}} \pm 4.02$ & 133 & $336.21^{\mathrm{b}} \pm 3.33$ & 87 & $353.61^{\mathrm{b}} \pm 3.74$ \\
\hline Age, $d$ & 116 & $420.15^{\mathrm{a}} \pm 1.35$ & 133 & $415.33^{b} \pm 1.33$ & 87 & $400.87^{\mathrm{c}} \pm 1.80$ \\
\hline
\end{tabular}

${ }^{\mathrm{a}-\mathrm{c} M e a n s}$ within a row with different superscripts differ $(P<0.05)$.

${ }^{1}$ Chute scores ( 1 to 6 ) were assigned by trained observers using the standardized scoring method recommended by the Beef Improvement Federation (2010).

Fecal samples were collected (d 0) while the heifers were restrained to avoid contamination. Samples were stored in individual containers on ice until they could be delivered to the lab and frozen at $-20^{\circ} \mathrm{C}$. Blood samples were collected via venipuncture in the caudal vein or artery into $15-\mathrm{mL}$ evacuated tubes with 18 -gauge $\times 1.5$-inch needles at AI. Samples were immediately cooled and transported to the lab, where they were refrigerated for at least $8 \mathrm{~h}$ before serum was harvested by centrifugation $(2,400 \times g)$ for $20 \mathrm{~min}$ at $4^{\circ} \mathrm{C}$.

\section{Laboratory Analysis}

Serum was stored at $-20^{\circ} \mathrm{C}$ until assayed. Serum concentrations of cortisol were determined using an RIA kit specific to bovine serum (Coat-A-Count Cortisol, Siemens Medical Solutions Diagnostics, Malvern, PA). The average intra- and interassay CV were $12 \%$ and $3.5 \%$, respectively.

Quantification of fecal corticosterone levels was modeled after protocols outlined by Huber et al. (2003). Concentrations of fecal corticosterone were determined using a commercial RIA kit (MP Biomedicals, Solon, $\mathrm{OH})$ validated for use on bovine samples in July 2012. For extraction, $0.5 \mathrm{~g}$ of thawed fecal matter was placed into $15-\mathrm{mL}$ centrifuge tubes, $4.5 \mathrm{~mL}$ of $80 \%$ methanol was added, and the tubes were placed in a lab rack vortexer for $40 \mathrm{~min}$. Following vortexing, tubes were centrifuged at $3,000 \times g$ for $15 \mathrm{~min}$. The amount of corticosterone in the supernatant was determined by the $\mathrm{I}_{25}$-Corticosterone RIA. The average intra- and interassay $\mathrm{CV}$ were $3.5 \%$ and $5.5 \%$, respectively.

\section{Statistical Analysis}

Statistical analysis for this study was performed with SAS (SAS Inst. Inc., Cary, NC). Logistic regression was used to determine the factors that influenced pregnancy rate. Contemporary group was fit as a fixed effect, whereas fecal cortisol (FC), blood cortisol (BC), $\mathrm{EV}, \mathrm{CS}, \mathrm{BW}$, and age were all included as covariates.

The effects of semen deposition site (horn/body) and flunixin meglumine (Banamine, Intervet Inc., Merck Animal Health) treatment were found to be nonsignificant $(P>0.37)$, so contemporary group was defined as location. Correlation coefficients were also calculated between FC, BC, EV, CS, BW, and age using the MANOVA procedure. Data from all locations were analyzed jointly as well as separated by ranch because of differences in ambient temperature and drought conditions at each location.

\section{RESULTS AND DISCUSSION}

\section{Least Squares Mean Differences}

Least squares means for FC, BC, EV, CS, BW, and age by location are reported in Table 1 . The LS mean difference in $\mathrm{FC}$ was greatest for ranch 1 and least at ranch 2 , with ranch 3 intermediate $(P<0.0001)$. Frequency of fecal corticosterone by ranch is illustrated in Fig. 1. Blood cortisol did not differ between ranches 1 and $2(P>0.12)$. Ranch 3, however, exhibited greater $\mathrm{BC}$ concentrations than both ranches 1 and $2(P<$ $0.0001, P<0.0001$, respectively). Frequency of BC by ranch is illustrated in Fig. 2. Exit velocity was the lowest for ranch 1 compared with ranches 2 and $3(P<$ $0.0001, P=0.0016$ ), greatest at ranch 3 compared with ranches 1 and $2(P=0.0016, P<0.0001)$, and intermediate for ranch $2(P<0.0001)$. Frequency of exit velocity by ranch is illustrated in Fig. 3. Chute score was greatest at ranch 1 compared with ranches 2 and $3(P<$ 0.0001, $P<0.0001)$, lowest for ranch 2 compared with ranches 1 and $3(P<0.0001, P=0.04)$, and intermediate for ranch 3 compared with ranch $2(P=0.04)$ and ranch $1(P<0.0001)$. Frequency of CS by ranch is illustrated in Fig. 4. Body weight for ranch 1 was greater than that for ranch $2(P=0.0021)$ but less than that for ranch $3(P=0.0015)$. Body weight was not different 


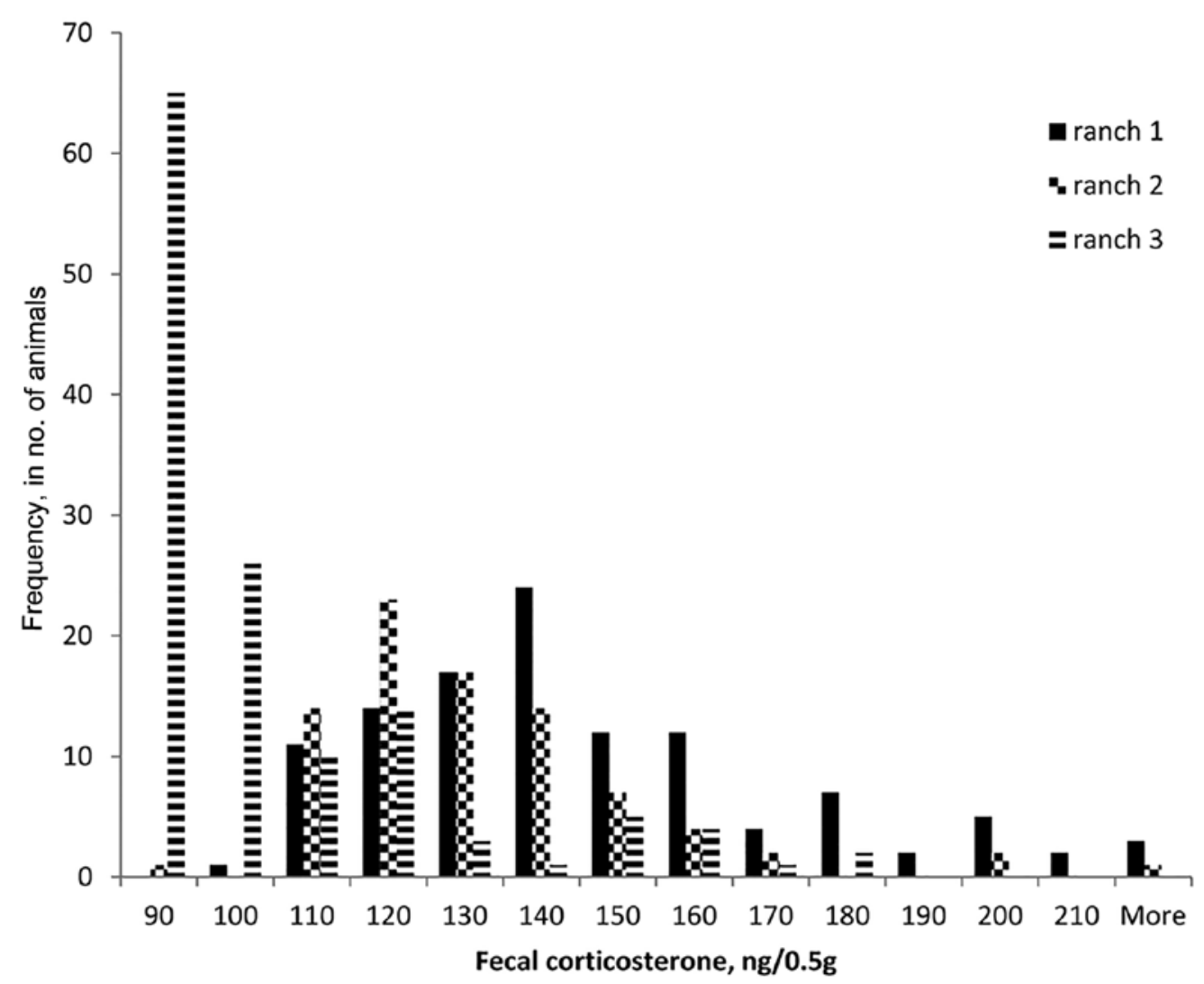

Figure 1. Frequency of fecal corticosterone (ng/0.5 g) by ranch.

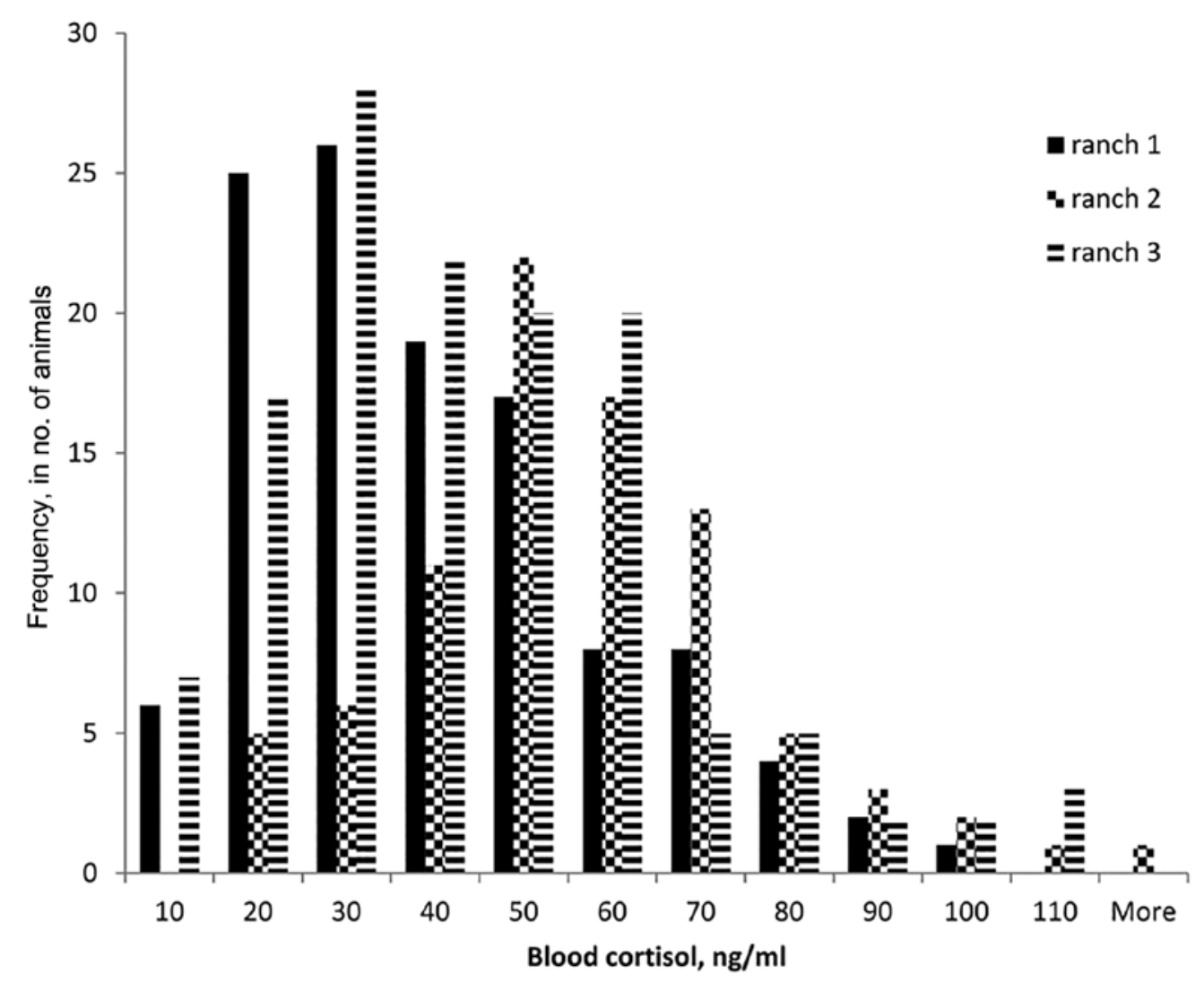

Figure 2. Frequency of blood cortisol (ng/mL) by ranch. 


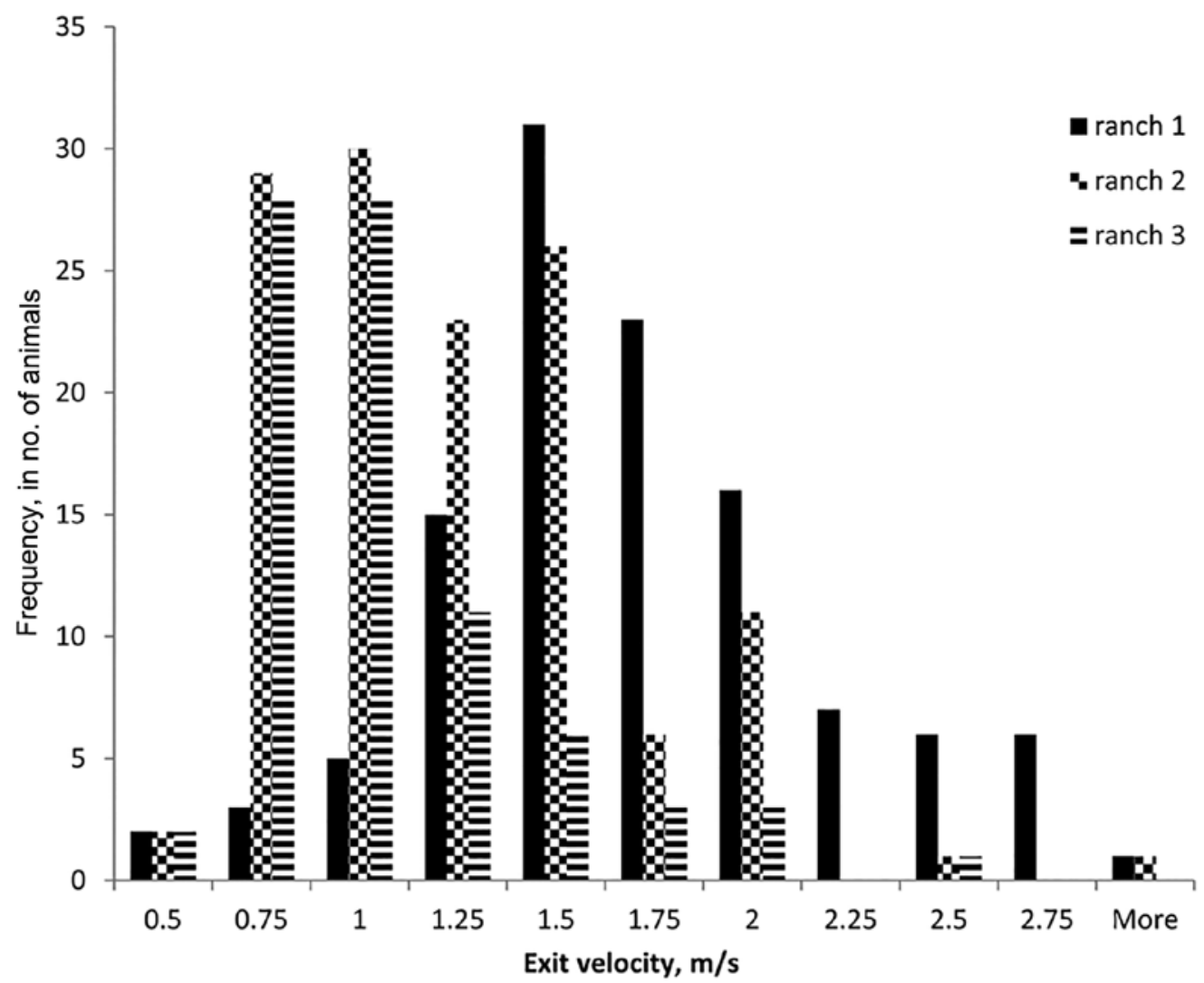

Figure 3. Frequency of exit velocity $(\mathrm{m} / \mathrm{s})$ by ranch.

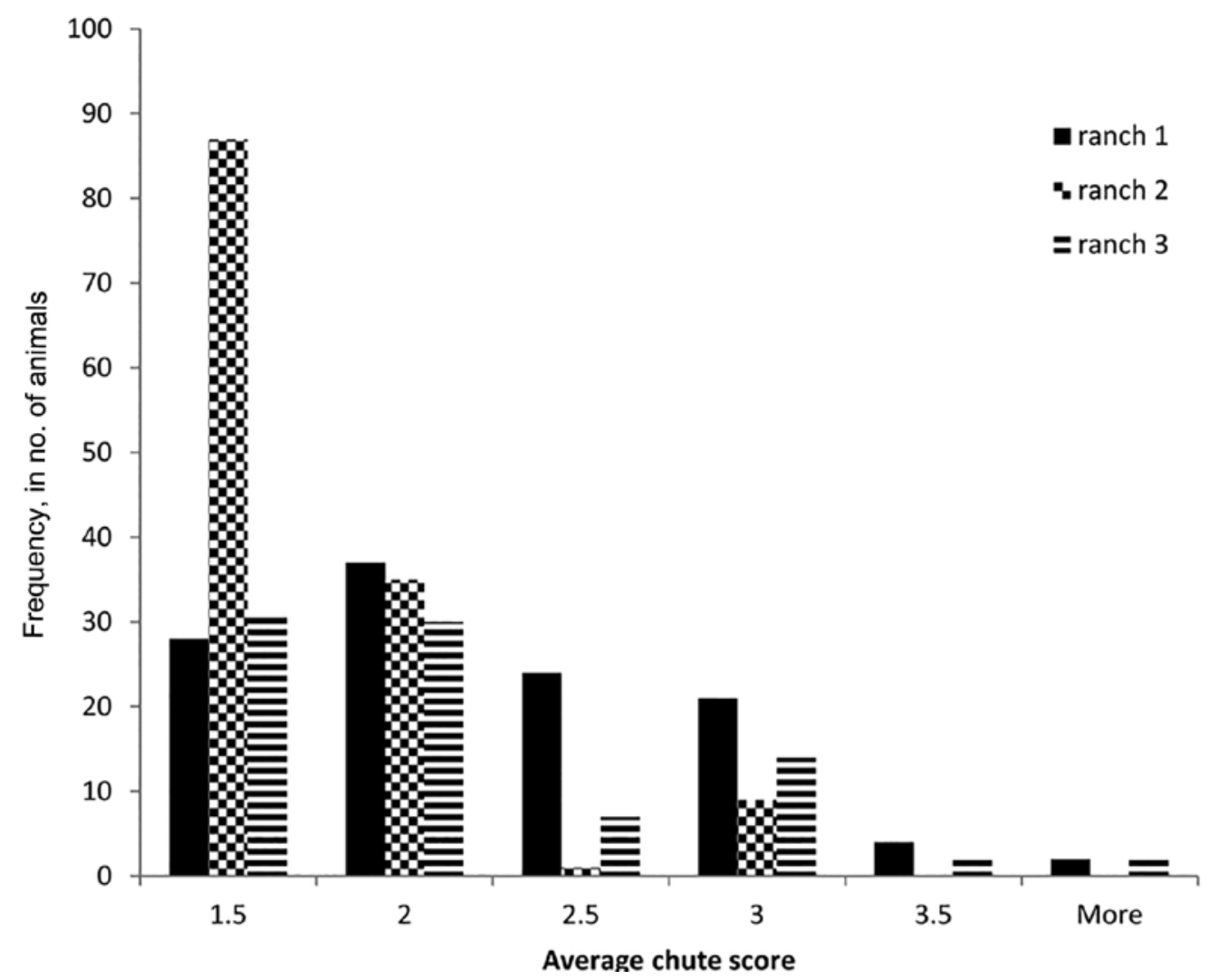

Figure 4. Frequency of average chute score by ranch. 
for ranches 2 and $3(P>0.73)$. Animals at ranch 1 were greater in age than those at ranches 2 and $3(P=0.02, P$ $<0.0001)$, ranch 3 animals were younger than animals at both ranches 1 and $2(P<0.0001, P<0.0001)$, and animals at ranch 2 were of intermediate age compared with ranches $3(P<0.0001)$ and $1(P=0.02)$.

\section{Predictors of 30-d Pregnancy}

Pregnancy rate, defined here as the percentage of heifers pregnant at $30 \mathrm{~d}$ after breeding, was $60.87 \%$ for ranch $1,34.59 \%$ for ranch 2 , and $50.00 \%$ for ranch 3 . The power of our test detected no significant predictors of 30-d pregnancy with odds ratio confidence intervals not different than 1 for ranches 2,3 , and the combined data (see Table 2). Chute score $(P<0.04)$ and BW ( $P$ $<0.0082)$ were determined to have odds ratio estimates different from 1 as significant predictors of $30-\mathrm{d}$ pregnancy for ranch 1 . The odds ratio estimate for CS was significant, meaning that a 1 -unit increase in average CS will reduce the odds of pregnancy at ranch 1 by $48.1 \%$. Therefore, poor temperament as indicated by increasing CS was associated with a decreased probability of becoming pregnant. This is consistent with the findings of Cooke et al. (2009), who reported that physiological responses associated with temperament can influence the probability of cows becoming pregnant during the breeding season. The odds ratio estimate for weight is somewhat more difficult to interpret because a $1-\mathrm{kg}$ increase in weight will decrease the odds of pregnancy by $2.2 \%$. In contrast to expectations, an increase in heifer weight at breeding was associated with a decrease in the probability of becoming pregnant.

\section{Correlations}

Table 3 contains correlation coefficients between variables for the combined data as well as the individual ranches. A positive correlation between $\mathrm{FC}$ and age $(0.09, P<0.0003)$ was found for ranch 1 , meaning as age increased, so did fecal corticosterone concentration. Fecal cortisol was positively correlated with $\mathrm{BC}$ at ranch $3(0.28, P=0.01)$, meaning as $\mathrm{FC}$ concentrations increased, so did $\mathrm{BC}$ concentrations. This result indicates a relationship between cortisol reactions for acute and long-term indicators of stress as measured by cortisol and corticosterone.

Blood cortisol was positively correlated with $\mathrm{EV}$ for the combined data $(0.22, P<0.0001)$ and for ranches 1 and $2(0.26, P<0.0062 ; 0.24, P<0.0062)$, meaning that as $\mathrm{BC}$ increased, $\mathrm{EV}$ also increased. This result shows that more temperamental cattle experienced greater physiological stress during handling, as indicated by cortisol, which is consistent with the find-
Table 2. Odds ratio estimates (ORE), confidence limits, and $P$-value for the logistic regression of $30-\mathrm{d}$ pregnancy on fecal cortisol (FC), blood cortisol (BC), exit velocity (EV), average chute score (CS), weight, and age for all data, ranch 1 , ranch 2, and ranch 3

\begin{tabular}{|c|c|c|c|c|}
\hline Variable & ORE & \multicolumn{2}{|c|}{ Confidence limits } & $P$-value \\
\hline \multicolumn{5}{|l|}{$\overline{\mathrm{FC}, \mathrm{ng} / 0.5 \mathrm{~g}}$} \\
\hline All data & 1.006 & 0.998 & 1.015 & 0.1451 \\
\hline Ranch 1 & 1.009 & 0.995 & 1.023 & 0.2059 \\
\hline Ranch 2 & 1.002 & 0.987 & 1.018 & 0.7509 \\
\hline Ranch 3 & 1.005 & 0.985 & 1.024 & 0.6478 \\
\hline \multicolumn{5}{|l|}{$\mathrm{BC}, \mathrm{ng} / \mathrm{mL}$} \\
\hline All data & 1.007 & 0.995 & 1.018 & 0.2379 \\
\hline Ranch 1 & 1.005 & 0.985 & 1.025 & 0.6399 \\
\hline Ranch 2 & 1.005 & 0.987 & 1.023 & 0.6032 \\
\hline Ranch 3 & 1.010 & 0.986 & 1.034 & 0.4136 \\
\hline \multicolumn{5}{|l|}{$\mathrm{EV} \mathrm{m} / \mathrm{s}$} \\
\hline All data & 0.949 & 0.677 & 1.332 & 0.7639 \\
\hline Ranch 1 & 2.499 & 0.976 & 6.398 & 0.0562 \\
\hline Ranch 2 & 0.786 & 0.441 & 1.400 & 0.4131 \\
\hline Ranch 3 & 0.821 & 0.482 & 1.396 & 0.4660 \\
\hline \multicolumn{5}{|l|}{$\mathrm{CS}^{1}$} \\
\hline All data & 0.706 & 0.494 & 1.009 & 0.0560 \\
\hline Ranch 1 & 0.519 & 0.283 & 0.954 & 0.0348 \\
\hline Ranch 2 & 0.609 & 0.301 & 1.232 & 0.1675 \\
\hline Ranch 3 & 0.933 & 0.496 & 1.753 & 0.8286 \\
\hline \multicolumn{5}{|l|}{ Weight, kg } \\
\hline All data & 0.993 & 0.986 & 1.001 & 0.0724 \\
\hline Ranch 1 & 0.978 & 0.962 & 0.994 & 0.0082 \\
\hline Ranch 2 & 0.998 & 0.983 & 1.006 & 0.3874 \\
\hline Ranch 3 & 1.000 & 0.986 & 1.014 & 0.9950 \\
\hline \multicolumn{5}{|l|}{ Age, d } \\
\hline All data & 1.001 & 0.984 & 1.017 & 0.9316 \\
\hline Ranch 1 & 1.016 & 0.983 & 1.049 & 0.3471 \\
\hline Ranch 2 & 0.996 & 0.968 & 1.024 & 0.7681 \\
\hline Ranch 3 & 0.983 & 0.952 & 1.014 & 0.2727 \\
\hline
\end{tabular}

${ }^{1}$ Chute scores ( 1 to 6 ) were assigned by trained observers using the standardized scoring method recommended by the Beef Improvement Federation (2010).

ings of Curley et al. (2006) and Cooke et al. (2009). Blood cortisol was negatively correlated with age for the combined data $(-0.12, P<0.04)$ and for ranch 2 $(-0.19, P=0.03)$; in other words, as BC increased, age seemed to decrease, meaning younger animals tended to have higher BC concentrations.

Exit velocity was positively correlated with $\mathrm{CS}$ for the combined data $(0.24, P<0.0001)$, ranch $1(0.20, P$ $=0.03)$, and ranch $2(0.41, P<0.0001)$. The correlation is intuitive, meaning that as EV increased for an animal, average CS also increased. This result is consistent with those of Curley et al. (2006), who found that EV and CS were positively correlated. Exit velocity was negatively correlated with both BW and age for both the combined data $(-0.15, P<0.0084 ;-0.12$, $P=0.03)$ and for ranch $2(-0.34, P<0.0001 ;-0.24, P$ 
Table 3. Phenotypic partial correlation coefficients (with $P$-values below) between fecal cortisol (FC), blood cortisol (BC), exit velocity (EV), average chute score (CS), weight, and age for data from all ranches, ranch 1 , ranch 2 , and ranch 3

\begin{tabular}{|c|c|c|c|c|c|c|}
\hline Variable & $\mathrm{FC}$ & $\mathrm{BC}$ & EV & CS & Weight & Age \\
\hline \multicolumn{7}{|l|}{$\mathrm{FC}, \mathrm{ng} / 0.5 \mathrm{~g}$} \\
\hline All data & 1.00 & -0.01 & 0.01 & -0.05 & -0.04 & 0.09 \\
\hline Ranch 1 & 1.00 & -0.12 & -0.07 & -0.02 & 0.01 & $0.34 * * *$ \\
\hline Ranch 2 & 1.00 & -0.05 & -0.02 & -0.07 & -0.09 & 0.01 \\
\hline Ranch 3 & 1.00 & $0.28 *$ & $0.12-$ & -0.10 & -0.07 & -0.17 \\
\hline \multicolumn{7}{|l|}{$\mathrm{BC}, \mathrm{ng} / \mathrm{mL}$} \\
\hline All data & & 1.00 & $0.22 * * *$ & $=0.09$ & -0.09 & $-0.12^{*}$ \\
\hline Ranch 1 & & 1.00 & $0.26^{*}$ & 0.03 & 0.04 & -0.02 \\
\hline Ranch 2 & & 1.00 & $0.24 *$ & 0.09 & $-0.23 *$ & $-0.19^{*}$ \\
\hline Ranch 3 & & 1.00 & 0.17 & 0.18 & -0.00 & -0.12 \\
\hline \multicolumn{7}{|l|}{$\mathrm{EV}, \mathrm{m} / \mathrm{s}$} \\
\hline All data & & & 1.00 & $0.24 * * *$ & $-0.15^{*}$ & $-0.12^{*}$ \\
\hline Ranch 1 & & & 1.00 & $0.20^{*}$ & 0.07 & 0.16 \\
\hline Ranch 2 & & & 1.00 & $0.41 * * *$ & $-0.34 * * *$ & $-0.24^{*}$ \\
\hline Ranch 3 & & & 1.00 & 0.11 & 0.00 & -0.16 \\
\hline \multicolumn{7}{|l|}{$\mathrm{CS}^{1}$} \\
\hline All data & & & & 1.00 & -0.08 & $-0.14^{*}$ \\
\hline Ranch 1 & & & & 1.00 & -0.06 & -0.08 \\
\hline Ranch 2 & & & & 1.00 & -0.11 & -0.15 \\
\hline Ranch 3 & & & & 1.00 & -0.03 & -0.19 \\
\hline \multicolumn{7}{|l|}{ Weight, $\mathrm{kg}$} \\
\hline All data & & & & & 1.00 & $0.42 * * *$ \\
\hline Ranch 1 & & & & & 1.00 & $0.36^{* * *}$ \\
\hline Ranch 2 & & & & & 1.00 & $0.47 * * *$ \\
\hline Ranch 3 & & & & & 1.00 & $0.39 * * *$ \\
\hline \multicolumn{7}{|l|}{ Age, d } \\
\hline All data & & & & & & 1.00 \\
\hline Ranch 1 & & & & & & 1.00 \\
\hline Ranch 2 & & & & & & 1.00 \\
\hline Ranch 3 & & & & & & 1.00 \\
\hline$* P<0.0$ & & & & & & \\
\hline
\end{tabular}

$<0.0061$, respectively). This inverse relationship suggests that as EV went up, both BW and age decreased. In other words, older, heavier animals have lower exit velocities than younger, faster animals, a difference that indicates a calmer temperament in older, heavier animals as measured by EV.

Average CS was found to be negatively correlated with age for the combined data $(-0.14, P=0.01)$. According to this result, older animals would have decreased average CS compared to younger animals, indicating a calmer temperament as measured by CS.

Weight was positively correlated with age for the combined data $(0.42, P<0.0001)$, ranch $1(0.36, P<$ $0.0001)$, ranch $2(0.47, P<0.0001)$, and ranch $3(0.39, P$ $<0.0002)$. As expected, BW increased steadily with age.

\section{Conclusions}

Our data generally indicated that animals with increased age and weight were associated with better temperament, as indicated by decreased $\mathrm{BC}, \mathrm{EV}$, and CS. Although the results from our combined data were inconclusive for predictors of 30-d pregnancy, results from ranch 1 indicated that $\mathrm{CS}$ and $\mathrm{BW}$ were related to $30-\mathrm{d}$ pregnancy rates. This result, in addition to the amount of variation in measures of temperament and reproductive status at all locations, indicates room for improvement in these traits. Interactions between temperament and reproductive success merit further investigation and could prove conclusive with a data set of sufficient size.

\section{LITERATURE CITED}

Beckman, D. W., S. E. Speidel, B. W. Brigham, D. J. Garrick, and R. M. Enns. 2005. Genetic parameter estimates for docility in Limousin cattle. Proc. West. Sect. Am. Soc. Anim. Sci. 56:109-111.

Beef Improvement Federation. 2010. Guidelines for uniform beef improvement programs. 9th ed. Beef Improv. Fed., Raleigh, NC.

Burrow, H. M., G. W. Seifert, and N. J. Corbet. 1988. A new technique for measuring temperament in cattle. Proc. Aust. Soc. Anim. Prod. 17:154-157.

Busby, D. 2010. Disposition-Convenience trait or economically important. Choice, 72(67.9), 58-1.

Cammack, K. M., M. G. Thomas, and R. M. Enns. 2009. Reproductive traits and their heritablities in beef cattle. Prof. Anim. Sci. 25:154-157.

Cooke, R. F., J. D. Arlington, D. B. Araujoand, and G. C. Lamb. 2009. Effects of acclimation to human interaction on performance, temperament, physiological responses, and pregnancy rates of Brahman-crossbred cows. J. Anim. Sci. 87:4125-4132. doi:10.2527/jas.2009-2021

Curley, K. O., Jr., J. C. Paschal, T. H. Welsh Jr., and R. D. Randel. 2006. Technical note: Exit velocity as a measure of cattle temperament is repeatable and associated with serum concentration of cortisol in Brahman bulls. J. Anim. Sci. 84:3100-3103. doi:10.2527/jas.2006-055

Huber, S., R. Palme, and W. Arnold. 2003. Effects of season, sex, and sample collection on concentrations of fecal cortisol metabolites in red deer (Cervus elaphus). Gen. Comp. Endocrinol. 130:48-54. doi:10.1016/S0016-6480(02)00535-X 